\title{
Cost-Effectiveness of Repository Corticotropin Injection versus Standard of Care for the Treatment of Active Rheumatoid Arthritis
}

\author{
Jas Bindra' \\ Ishveen Chopra ${ }^{2}$ \\ John Niewoehner ${ }^{3}$ \\ Mary Panaccio ${ }^{3}$ \\ George J Wan ${ }^{3}$
}

'Falcon Research Group, North Potomac, MD, USA; ${ }^{2}$ Manticore Consultancy, Bethesda, MD, USA:

${ }^{3}$ Mallinckrodt Pharmaceuticals, Hampton, $\mathrm{NJ}$, USA
Correspondence: George J Wan Mallinckrodt Pharmaceuticals, 53

Frontage Road, Hampton, NJ, 08827, USA

Email george.wan@mnk.com
Introduction: Patients with active rheumatoid arthritis (RA) often have inadequately controlled symptoms and are unable to achieve remission or low disease activity despite aggressive treatment. This results in irreversible joint damage, adversely affecting patients' physical and social functioning. The objective was to estimate the cost-effectiveness of repository corticotropin injection (RCI) versus standard of care (SoC) in patients with active RA from the United States (US) payer and societal perspectives over two to three years.

Methods: An individual-level microsimulation was developed to generate individual trajectories for patients with RA, using data from a published Phase 4 trial of RCI. These trajectories report a patient's disease pathway and associated cost and quality-of-life outcomes. The incremental cost-effectiveness ratio (ICER) of RCI versus SoC was assessed using the literature-derived direct medical and indirect costs, and quality-adjusted life-years (QALY) derived from a Phase 4 trial of RCI. The uncertainty in base case estimates of the parameters was evaluated in the sensitivity analysis.

Results: Over two years, RCI has an incremental QALY gain of 1.591 and incremental cost of $\$ 183,965$ and $\$ 117,443$ from payer and societal perspective, respectively, resulting in an ICER of \$115,629/QALY and \$73,817/QALY compared to SoC. Over three years, RCI has an incremental QALY gain of 2.336 and incremental cost of $\$ 202,315$ and $\$ 104,506$ from payer and societal perspective, respectively, resulting in an ICER of \$86,607/QALY and $\$ 44,737 /$ QALY compared to SoC. Results from the probabilistic sensitivity analysis are consistent with those of the base case model.

Conclusion: RCI is a cost-effective strategy for patients with persistently active RA who are previously treated with disease-modifying anti-rheumatic drugs and corticosteroids compared to SoC over two to three years from the payer and societal perspectives at a US willingnessto-pay threshold of $\$ 150,000 / \mathrm{QALY}$. Further, the economic benefit of RCI is realized with improvement in a patient's clinical and health outcomes.

Keywords: Acthar $\left.{ }^{(}\right)$Gel, cost-effectiveness analysis, low-disease activity, repository corticotropin injection, rheumatoid arthritis

\section{Introduction}

Rheumatoid arthritis (RA) is a chronic, systemic immune-inflammatory disease that causes synovial inflammation, that leads to bone and cartilage damage in multiple joints, ${ }^{1}$ joint pain and stiffness, and functional disability. ${ }^{2,3}$ The estimated incidence and prevalence of RA among adults range from 5 to 50 per 100,000 and $0.5-1.0 \%$, respectively in developed countries. ${ }^{4}$ An estimated 1.3 million adults in the United 
States (US) are affected by RA. ${ }^{5}$ RA adversely affects patients' quality of life and work productivity and results in substantial healthcare resource utilization. ${ }^{6}$

The primary goal of RA treatment focuses on symptom relief or to delay or cease the course of disease progression. ${ }^{7}$ RA disease management guidelines recommend a treat-to-target approach, with the goal of achieving remission or low disease activity (LDA) if remission is not feasible. ${ }^{8,9}$ Conventional synthetic disease-modifying antirheumatic drugs (csDMARDs), biologic DMARDs (bDMARDs), and targeted synthetic DMARDs, which suppress inflammation are used to decelerate disease activity. ${ }^{7,10}$ Despite the use of DMARDs, the symptoms of RA are often inadequately controlled. ${ }^{10,11}$ A study from the British Society for Rheumatology Biologics Register for RA found that among patients who initiated the firstline bDMARD therapy in combination with tumor necrosis factor inhibitors, $6 \%$ did not respond to the therapy even after trying 3 classes of bDMARDs. ${ }^{12}$ These patients were classified as having refractory disease, ${ }^{12}$ estimated to be approximately 30,000 to 34,000 US patients. ${ }^{13,14}$ Uncontrolled refractory RA results in sustained irreversible joint damage adversely affecting patients' physical and social functioning. ${ }^{10,11}$ Glucocorticoids are a common treatment used to achieve rapid control of inflammation in patients with RA initiating or switching DMARD therapy. ${ }^{8,9}$ However, glucocorticoids may be limited in their use due to several adverse events. ${ }^{15}$ Glucocorticoid use for $>3$ months, at a high dose, results in rapid, persistent bone loss, which contributes to increased risk of osteoporosis and fractures and is of particular concern in patients with RA. ${ }^{1}$

Repository corticotropin injection (RCI; Acthar ${ }^{\circledR}$ Gel) is indicated as adjunctive therapy for short-term administration to tide the patient over an acute episode or exacerbation in RA by the US Food and Drug Administration (FDA) ${ }^{16} \mathrm{RCI}$ is a naturally sourced complex mixture of adrenocorticotropic hormone analogues and other pituitary peptides that functions as an agonist of all five melanocortin receptors. ${ }^{16}$ As an agonist of all five melanocortin receptors, it has several potential mechanistic pathways that may contribute to its therapeutic effects in RA. ${ }^{17}$ In clinical practice, it is typically utilized in RA patients who are inadequately controlled and/or unable to tolerate previously prescribed conventional treatments. The label was recently updated after the FDA was provided safety monitoring and reporting data spanning more than 60 years. In addition to modernizing the prescribing information, the statement "Common adverse reactions for Acthar Gel are similar to those of corticosteroids" was removed in the prescribing information highlights section of the label; however, the warnings and precautions section, which notes potential steroidogenic effects remains largely unchanged. ${ }^{16}$

RCI has shown significant, durable, and beneficial effects on disease activity in a published open-label Phase 4 trial. $63 \%$ of the patients with persistently active RA achieved LDA based on the 28-Joint Disease Activity Score with Erythrocyte Sedimentation Rate (DAS28-ESR) at 12 weeks. Further, the sustained response was maintained during the randomized withdrawal phase (placebocontrolled) over the course of 12 weeks. Significant and clinically meaningful improvement in patient-reported outcomes (disability, fatigue, and work productivity) were also observed during the 12-week open-label phase and the outcomes persisted throughout the 12-week randomized withdrawal phase. ${ }^{18}$ A retrospective chart review study reported that $78 \%$ of RA patients treated with RCI had an improvement based on physician assessment. ${ }^{19}$ An observational administrative claims-based analysis of treatment patterns, healthcare utilization, and cost of RCI in patients with RA suggests a potential for a reduction in medical service use and associated costs with RCI by approximately $33 \%{ }^{20}$ Together these data suggest a potential for improvement in patient's health outcomes and an overall reduction in cost for disease management.

Although there is evidence of a favorable clinical profile of RCI, data on the economic benefit of using RCI for the treatment of patients with active RA is limited. The objective of the current study was to estimate the costeffectiveness of RCI versus standard of care (SoC) in patients with active RA despite aggressive treatment from the US payer and societal perspectives over three years. A 3-year time horizon was selected considering the US payer perspective.

\section{Methods \\ Model Overview}

An individual-level microsimulation was developed in Microsoft $^{\circledR}$ Excel 2019. The microsimulation model generates individual patient trajectories. These trajectories report a patient's disease pathway considering the therapy and its outcomes on disease activity and the subsequent consequence costs and quality of life. The incremental cost-effectiveness ratio (ICER) of RCI versus SoC was 
assessed using direct medical costs, indirect costs, and quality-adjusted life-years (QALY) over three years from the US payer and societal perspectives. The principal evidence source used to derive clinical and patient outcomes parameter values was from a published open-label Phase 4 randomized, double-blind, placebo-controlled withdrawal trial. This clinical trial consisted of two phases. In the first phase, all subjects received open-label RCI ( 80 $\mathrm{U})$ twice weekly for 12 weeks. In the second phase, only those with LDA based on DAS28-ESR were randomly assigned to receive either RCI $(80 \mathrm{U})$ or placebo twice weekly during the 12 -week double-blind period. ${ }^{18}$ Detailed results of this clinical trial conducted over 24 weeks comparing efficacy, safety, and tolerability of RCI with placebo have been described elsewhere. ${ }^{18}$ The subjects included had active RA despite treatment with prednisone (or an equivalent) and one or two csDMARDs or one bDMARD. ${ }^{18}$ Patient profiles were generated using generalized linear modeling with gamma distributions and $\log$ link functions based on the data in the Phase 4 trial. ${ }^{18}$ This modeling approach maintains correlations in patient clinical characteristics observed in the clinical trial. Further, validations including descriptive statistics and correlations ensured that the relationship between parameters was preserved with this approach.

\section{Model Structure and Relationships}

The model structure is presented in Figure 1. Each patient history starts when they enter the model at cycle 0 with a given score on the DAS28-ESR, which reflects the number of swollen joints (0-28), the number of tender joints (0-28), patient's global assessment of disease activities (0-10), and ESR (0-20). The DAS28-ESR for the patients in the previous cycle determines if a patient receives RCI in a given cycle. A patient with DAS28ESR $<3.2$ (LDA achievement) in the previous cycle does not receive treatment in the current cycle. On the contrary, a patient who did not achieve LDA in the previous cycle receives RCI treatment in the current cycle. Patients who do not receive RCI follow the trajectory of patients on placebo in part 2 (randomization arm) of Phase 4 trial. ${ }^{18}$ Patients who receive RCI follow distribution derived from the RCI arm of part 2 of Phase 4 trial. $^{18}$ Further, patients who fail RCI treatment stay on the treatment for subsequent cycles until they achieve LDA. Treatment decisions are made in 3-month cycles, for 1000 patients initiating on RCI or SoC. For each patient, the starting scores on the four DAS28-ESR domains are derived by Monte-Carlo simulation using a multivariate gamma distribution, which is estimated using the shape and scale of the parameters from the Phase 4 sample population. ${ }^{18}$ The parameters including swollen joint count (SJC), tender joint count (TJC), ESR, and Patient's Global Assessment of Disease Activities score were modeled based on the Phase 4 trial data. The parameters including the DAS28-ESR, Health Assessment Questionnaire Disability Index (HAQ-DI), the visual analog scale for pain (VAS), and American College of Rheumatology (ACR) 20, ACR50, and ACR70 were derived from the modeled parameter estimates.

The effect of RCI was modeled by shifts in the distribution means, reflecting improvements in scores. These shifts were again generated using a multivariate gamma distribution as estimated by the sample means and covariance as observed in phase 4 clinical trial. While the shifts in the means capture the improvements in the scores, the covariance matrix captures the positive correlation between the four domains. Since this correlation is not perfect, patients may improve in one domain but not necessarily on another domain of the DAS28-ESR. The DAS28-ESR was calculated using the equation: ${ }^{21}$

$$
\begin{aligned}
\text { DAS28-ESR }= & 0.28 \times \sqrt{S J C}+0.56 \times \sqrt{T J C} \\
& +0.70 \times \ln (\text { ESR })+0.014 \times \text { Global Health }
\end{aligned}
$$

where, DAS28-ESR, 28-joint disease activity score with erythrocyte sedimentation rate; $\mathrm{SJC}=$ swollen joint count; $\mathrm{TJC}=$ tender joint count; Global health was based on the scores on Patient's Global Assessment of Disease Activities.

Further, each patient is given a score on the patient's global assessment of disease activities (0-10), and a score for HAQ-DI (0-3) and VAS (0-100) based on the DAS28ESR score. The initial HAQ-DI score (cycle 0) was calculated using the following equation. The equation is modified using the complete equation for calculating HAQ-DI in cycles $0+{ }^{22}$

$$
\mathrm{HAQ}-\mathrm{DI}_{0}=-0.037+0.205 \times \mathrm{DAS} 28-\mathrm{ESR}_{0}
$$

The HAQ-DI scores in the subsequent cycles (cycle 1+) were calculated as a function of time, previous DAS28ESR, and HAQ-DI scores. ${ }^{22}$ 


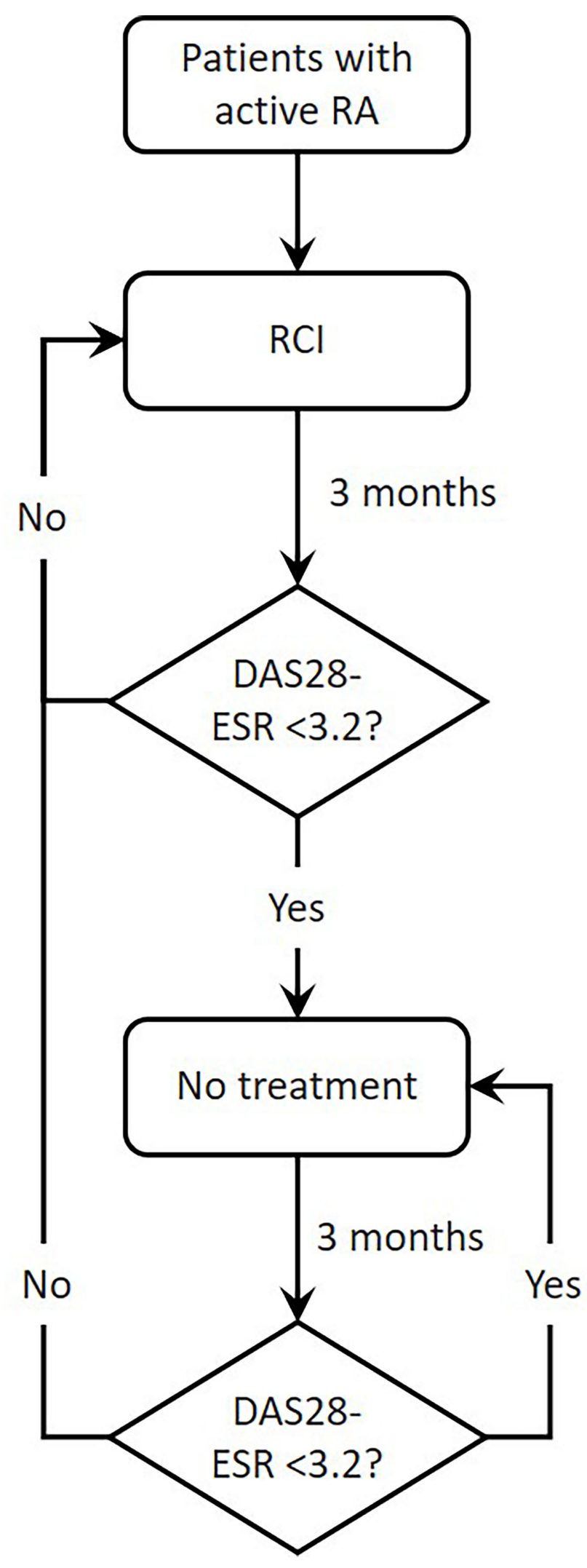

Figure I Framework for individual-level microsimulation for assessing the costeffectiveness of $\mathrm{RCl}$ for the treatment of RA. Clinical and economic outcomes are assessed every 3 months.

Abbreviations: DAS28-ESR, 28-joint disease activity score with erythrocyte sedimentation rate; $\mathrm{RA}$, rheumatoid arthritis; $\mathrm{RCl}$, repository corticotropin injection.

$$
\begin{aligned}
& \text { HAQ-DI }{ }_{n}=-0.037+0.044 \times \ln (\mathrm{n})+0.213 \times \mathrm{DAS}_{28}-\mathrm{ESR}_{n-1} \\
& +0.183 \times\left(\mathrm{DAS}_{28}-\mathrm{ESR}_{n}-\mathrm{DAS}^{\left.28-\mathrm{ESR}_{n-1}\right)}\right. \\
& +0.022 \times \mathrm{DAS}_{28}-\mathrm{ESR}_{n-1} \times\left(\mathrm{DAS}_{2} 8-\mathrm{ESR}_{n}\right. \\
& \left.- \text { DAS28-ESR }_{n-1}\right)+0.234 \times \text { HAQ-DI }{ }_{n-1}
\end{aligned}
$$

where, $\mathrm{n}=$ cycle number.

VAS score each cycle was calculated from the utility, HAQ-DI, and DAS28-ESR. ${ }^{23}$

$$
\mathrm{VAS}=\frac{\begin{array}{l}
- \text { Utility }-0.21 \times \text { HAQ-DI }-0.01 \\
\times \text { DAS28-ESR }+0.95
\end{array}}{0.24}
$$

The DAS28-ESR components were used to predict ACR20, ACR50, and ACR70 responses at each cycle. The ACR is a composite measure defined as both improvement of $20 \%$ in the number of tender and number of swollen joints, and a $20 \%, 50 \%$, or $70 \%$ improvement in three of the following five criteria: (i) patient global assessment, (ii) physician global assessment, (iii) functional ability measure (most often HAQ-DI), (iv) VAS pain scale, and (v) ESR. ${ }^{24}$

\section{Key Inputs Clinical Data}

Clinical data included baseline number of swollen joints, number of tender joints, and ESR that were derived from the Phase 4 trial data. ${ }^{18}$ Clinical characteristics are presented in Supplementary Table 1. Due to the short timeframe of the model, mortality was not considered in the model.

\section{Healthcare Resource Utilization and Costs}

Economic data were obtained from the peer-reviewed published literature (Table 1). Economic data were linked to a patient's DAS28-ESR and/or HAQ score. Unless otherwise specified, all costs are discounted at 3.0\% annually and reported in 2020 United States Dollars (USD).

Medication costs were sourced from the IBM Micromedex ${ }^{\circledR}$ Red Book and the frequency of use of RCI was based on dispensing data from specialty pharmacies, from the last 12 months as of March 29, 2019. The model assumes that the patients receive a dose of RCI when their DAS28-ESR $\geq 3.2$. The use of other medications, comprising csDMARDs, bDMARDs, and corticosteroids, were derived from Phase 4 clinical trial ${ }^{18}$ and published literature. The costs of these treatments were sourced from published literature.

Direct costs of RA management included RA-related hospitalization, outpatient, primary care, and a specialist visit, rehabilitation, and laboratory testing and imaging 
costs. The costs related to total joint replacement surgery were also considered. ${ }^{24,25}$ Pain-related costs included in the model were based on the pain severity. ${ }^{26,27}$ RA-related opioid abuse costs were also included in the model. Estimates from the literature suggest that up to $40 \%$ of patients with RA are regular users of opioids and the effects of DMARDs are minimal in reducing opioid use. Although the literature supports the efficacy of short-term opioids for the improvement in pain, long-term use is associated with reduced efficacy and increased safety concerns. The data supporting the use of long-term opioid use in patients with RA is poor, however, rheumatologists can adhere to best practices for determining when and if the initiation of opioids is appropriate. Identification of the nature of the pain can help determine the appropriate course of treatment. ${ }^{28-30}$

Indirect costs due to the productivity loss for the patients and the additional cost of caregiving were applied in the model from the societal perspective. The proportion of work loss was derived from Work Productivity and Activity Impairment scores from the Phase 4 trial. ${ }^{18}$ For estimating the indirect costs, the model used $\$ 55,018$ as the per capita income in the US (inflated to 2020 USD using Consumer Price Index-All Urban Consumers; annual per capita income is $\$ 53,490$ in $2019),{ }^{31} \$ 4,411$ for the annual cost of caregiving for $\mathrm{RA},{ }^{32}$ and $\$ 22,360$ for the cost of work-related training. ${ }^{32}$

\section{Health Utilities}

Utilities are derived from the HAQ-DI and VAS using regression estimates, consistent with the published methodology. ${ }^{33,34}$ This method accounts for the correlation between HAQ-DI and VAS. Unless otherwise specified, all utilities are discounted at $3.0 \%$ annually.

\section{Analyses}

\section{Base Case Analysis}

Total costs and QALYs were compared between RCI and SoC at 2 and 3 years from both US payer and societal perspectives. From a payer perspective, total costs included direct medical costs (costs paid by third party-payers) and from a societal perspective, total costs comprised indirect costs (productivity loss, work-related training, and caregiving) in addition to the direct medical costs. The primary outcome was the discounted ICER defined as the difference in costs divided by the difference in QALYs of RCI and SoC. The secondary outcomes included incremental cost per patient improvement in outcome (cost-benefit). The benefit was defined as the achievement of LDA, ACR 20, ACR 50, or ACR 70 response.

\section{Probabilistic Sensitivity Analysis}

Estimates for sensitivity analysis were generated from gamma and beta distributions as appropriate. The basecase assumptions and alternative values for these assumptions were tested and fully explored in the probabilistic sensitivity analysis (PSA) combined bootstrapping with random draws from uncertainty distributions. By bootstrapping the data from the randomized clinical trial using appropriate distributions, we obtained uncertainty margins surrounding the parameters.

\section{Results \\ Base Case Analysis}

The use of RCI results in an incremental cost of \$183,965 and an incremental QALY gain of 1.591, resulting in an ICER of $\$ 115,629$ per QALY compared to that of SoC from the payer perspective over two years (Table 2). From the societal perspective over two years, RCI has an incremental cost of $\$ 117,443$ and an incremental QALY gain of 1.591 , resulting in an ICER of $\$ 73,817$ per QALY compared to that of SoC. The ICER was lower from the payer $(\$ 86,607)$ and a societal perspective $(\$ 44,737)$ over three years. A detailed breakdown of costs for two and three years is provided in Supplementary Table 2.

The results showed similar trends with other costbenefit outcomes. Over 3 years, an additional 8.019, $2.945,1.468$, and 0.615 patients per year achieved LDA, ACR20, ACR50, and ACR70, respectively. This was associated with an incremental cost-benefit of $\$ 252, \$ 687$, $\$ 1,378$, and $\$ 3,290$, respectively from the payer perspective and $\$ 130, \$ 355, \$ 712$, and $\$ 1,699$, respectively from the societal perspective.

\section{Probabilistic Sensitivity Analysis}

The PSA randomly sampled parameters from within chosen distributions over 1,000 iterations. The parameters for sensitivity analysis are provided in Supplementary Tables $3-5$. The findings from the PSA are consistent with the base case analysis; RCI is costeffective compared to the SoC over 2 years (ICER: $\$ 122,643$ per QALY; 95\% confidence interval: $\$ 57,338, \$ 187,948$ per QALY [payer perspective]). The cost-effectiveness acceptability curve shows that RCI is cost-effective $65.3 \%$ of the iterations at a willingness-topay threshold of $\$ 150,000$ per QALY over 2 years from a payer perspective (Figure 2). 
Table I Healthcare Resource Utilization and Associated Costs

\begin{tabular}{|c|c|c|c|c|c|c|}
\hline Parameter & \multicolumn{5}{|c|}{ Value } & Reference \\
\hline \multicolumn{7}{|l|}{ Treatment costs } \\
\hline Cost of $\mathrm{RCl}$ (per pack) & \multicolumn{5}{|c|}{$\$ 39,864$} & IBM Micromedex ${ }^{\circledR}$ Red Book ${ }^{38}$ \\
\hline $\mathrm{RCl}$ use (I2 months) & \multicolumn{5}{|c|}{7.59 packs } & $\begin{array}{l}\text { Data on File using dispensing data from specialty pharmacies, } \\
\text { from the last } 12 \text { months as of March } 29,2019\end{array}$ \\
\hline \multicolumn{7}{|l|}{ Medication utilization } \\
\hline \multicolumn{7}{|l|}{ Standard of care } \\
\hline csDMARDs & \multicolumn{5}{|c|}{$96.9 \%$} & NCT02919761 ${ }^{39}$ \\
\hline Biologic DMARDs & \multicolumn{5}{|c|}{$23.9 \%$} & NCT02919761 ${ }^{39}$ \\
\hline Corticosteroids & \multicolumn{5}{|c|}{$90.3 \%$} & NCT0291976I 39 \\
\hline \multicolumn{7}{|l|}{$\mathrm{RCl}$} \\
\hline csDMARDs & \multicolumn{5}{|c|}{$35.9 \%\left(63.0 \%\right.$ reduction $\left.{ }^{\mathrm{a}}\right)$} & NCT02919761 ${ }^{39}$ \\
\hline Biologic DMARDs & \multicolumn{5}{|c|}{$10.0 \%\left(58.3 \%\right.$ reduction $\left.{ }^{\mathrm{a}}\right)$} & NCT02919761 ${ }^{39}$ \\
\hline Corticosteroids & \multicolumn{5}{|c|}{$47.3 \%\left(47.7 \%\right.$ reduction $\left.{ }^{\mathrm{a}}\right)$} & NCT02919761 ${ }^{39}$ \\
\hline \multicolumn{7}{|l|}{ Average cost of medications } \\
\hline Non-biologic DMARDs & \multicolumn{5}{|c|}{$\$ 2,775$} & Eisenberg Center at Oregon Health \& Science University $2008^{40}$ \\
\hline Biologic DMARDs & \multicolumn{5}{|c|}{$\$ 26,620$} & Eisenberg Center at Oregon Health \& Science University $2008^{40}$ \\
\hline Corticosteroids & \multicolumn{5}{|c|}{$\$ 391$} & Eisenberg Center at Oregon Health \& Science University $2008^{40}$ \\
\hline \multicolumn{7}{|l|}{ RA-related costs } \\
\hline HAQ-DI & $<0.60$ & $\begin{array}{c}0.60 \\
\text { to } 1.09\end{array}$ & & $\begin{array}{c}1.60 \\
\text { to } 2.09\end{array}$ & $\geq \mathbf{2} .1$ & \\
\hline RA-related hospitalization & $\$ 6,114$ & $\$ 8,009$ & & $\$ 8,713$ & $\$ 10,242$ & Wu $2017^{20}$ \\
\hline Outpatient costs & $\$ 438$ & $\$ 574$ & & $\$ 624$ & $\$ 734$ & Wu $2017^{20}$ \\
\hline Primary care and specialist visits & $\$ 559$ & $\$ 632$ & & $\$ 642$ & $\$ 777$ & Klimeš $2014^{41}$ \\
\hline Rehabilitation & $\$ 79$ & $\$ 107$ & & $\$ 212$ & $\$ 228$ & Klimeš $2014^{41}$ \\
\hline Laboratory testing and imaging & $\$ 298$ & $\$ 229$ & & $\$ 353$ & $\$ 806$ & Klimeš $2014^{41}$ \\
\hline \multicolumn{7}{|l|}{ Surgical costs } \\
\hline Rate of total joint replacement & \multicolumn{5}{|c|}{$2.9 \%$} & Onuoha $2017^{24}$ \\
\hline Cost of surgery & \multicolumn{5}{|c|}{$\$ 45,215$} & Clair $2016^{25}$ \\
\hline \multicolumn{7}{|l|}{ Pain-related costs ${ }^{b}$} \\
\hline Mild (VAS $\leq 3.5)$ & \multicolumn{5}{|c|}{$\$ 9,550$} & Lalonde $2014^{27}$ \\
\hline Moderate $(3.5<$ VAS $<7.5)$ & \multicolumn{5}{|c|}{$\$ 13,630$} & Lalonde $2014^{27}$ \\
\hline Severe (VAS $\geq 7.5)$ & \multicolumn{5}{|c|}{$\$ 12,363$} & Lalonde $2014^{27}$ \\
\hline \multicolumn{7}{|l|}{ RA-related opioid abuse } \\
\hline Prevalence in patients with moderate pain & & & & & & Lee $2019^{29}$ \\
\hline Prevalence in patients with severe pain & & & & & & Lee $2019^{29}$ \\
\hline Cost of opioid abuse & & & & & & White $2005^{30}$ \\
\hline Productivity loss costs (WPAI) & & & & & & \\
\hline DAS28-ESR & $<2.6$ & $\geq 2.6$ to $<3.2$ & $\geq 3.2$ & to $\leq 5.1$ & $>\mathbf{5 . 1}$ & \\
\hline Absenteeism & $11.7 \%$ & $13.1 \%$ & & $14.9 \%$ & $26.6 \%$ & NCT02919761 ${ }^{39}$ \\
\hline Presenteeism & $9.1 \%$ & $22.2 \%$ & & $28.0 \%$ & $54.3 \%$ & NCT0291976I ${ }^{39}$ \\
\hline Activity impairment & $17.2 \%$ & $27.9 \%$ & & $45.2 \%$ & $65.1 \%$ & NCT02919761 ${ }^{39}$ \\
\hline
\end{tabular}

Notes: ${ }^{a}$ Percent reduction in medication use was derived from Myung $2017 ;^{42}$ b thresholds for pain by VAS were derived from Boonstra $2014 .{ }^{26}$

Abbreviations: csDMARD, conventional synthetic DMARD; DAS28-ESR, 28-joint disease activity score with erythrocyte sedimentation rate; DMARD, disease-modifying anti-rheumatic drug; HAQ-DI, Health Assessment Questionnaire Disability Index; RA, rheumatoid arthritis; RCI, repository corticotropin injection; VAS, visual analog scale; WPAI, Work Productivity, and Activity Impairment. 


\section{Discussion}

The symptoms of RA persist despite the aggressive treatment with DMARDs, resulting in sustained irreversible joint damage negatively affecting patients' daily functioning and overall well-being. ${ }^{10,11} \mathrm{RCI}$ is a late-line treatment for patients with refractory RA having uncontrolled symptoms resulting in persistent high disease activity despite aggressive treatment with non-biologic and biologic DMARDs. Considering this specific subset of RA patients with active disease, the use of RCI may offer substantial benefits in clinical and health outcomes. Treatment of active RA with RCI has shown improvement in clinical and patient outcomes, ${ }^{18}$ however, the data on economic benefits is limited. Decision-making for chronic disease therapies should consider both clinical and economic impacts. The current model was developed to understand the potential healtheconomic implications of using RCI for the short-term treatment of an acute episode or exacerbations in patients with active RA. To the best of our knowledge, this is the first economic analysis to assess the cost-effectiveness of RCI versus $\mathrm{SoC}$ for the treatment of active RA.

The findings from the current analysis indicate that $\mathrm{RCI}$ is cost-effective compared to $\mathrm{SoC}$ at a willingness-to-pay threshold of $\$ 150,000$ per QALY over 2 years and at a threshold of $\$ 100,000$ per QALY over 3 years among patients who have active RA despite aggressive treatment with conventional medications. Therapies that offer substantial other benefits or intended for a special population are considered high "Care Value" within the cost/QALYs range of $\$ 100,000$ to $\$ 150,000 .^{35,36}$ The use of RCI was associated with reduced direct (excluding treatment) and indirect costs with gain in QALYs. The cost savings partially offset the higher initial treatment costs with RCI, preserving the cost-effectiveness of its use versus SoC. Moreover, cost savings were also evident from an improved clinical profile, including the achievement of LDA based on DAS28-ESR, ACR20/50/70 response. The cost-effectiveness of RCI is anticipated to improve considering rebates and drug price discounts.

Although the cost of treatment is central to issues of access and affordability, the treatments should be considered in the context of value. Value in healthcare, defined as the efficiency with which interventions deliver outcomes with respect to their costs, ${ }^{37}$ is typically measured using costeffectiveness metrics. The findings from this analysis provide insight into the potential economic impact of using RCI from the payer and societal perspectives. However, the findings should be interpreted in light of some limitations. First, the efficacy, work productivity, and utility data for the model were based on the data from a phase 4 clinical trial on RA, which may not reflect real-world outcomes. The model assumes some heterogeneity in the RA population; however, the presence of other inflammatory comorbidities may further exacerbate RA and enhance the value of RCI. Second, a simplified care paradigm was implemented for the model, ie, the patients who fail on RCI stay on treatment for subsequent cycles until they achieve a response. Third, patients who experience exacerbation after achieving LDA were assumed to resume the RCI treatment for subsequent cycles. This assumption may not reflect real-world treatment pathways in RA, which are complex, dependent on multiple factors, and highly individualized. Finally, the data on healthcare utilization and costs were obtained from the published literature and may result in under or over-estimation. However, a probabilistic sensitivity analysis was conducted

Table 2 Base Case Results for Incremental Cost-Effectiveness and Net Monetary Benefit of RCl versus SoC (2020 USD)

\begin{tabular}{|c|c|c|c|c|c|c|c|}
\hline Year & $\begin{array}{c}\text { Incremental } \\
\text { Costs }^{\mathrm{a}}\end{array}$ & $\begin{array}{c}\text { Incremental } \\
\text { QALYs }^{\mathrm{a}}\end{array}$ & ICER & $\begin{array}{c}\text { Incremental } \\
\text { Cost per LDA } \\
\text { Achieved }\end{array}$ & $\begin{array}{c}\text { Incremental Cost } \\
\text { per ACR20 } \\
\text { Achieved }\end{array}$ & $\begin{array}{c}\text { Incremental Cost } \\
\text { per ACR50 } \\
\text { Achieved }\end{array}$ & $\begin{array}{c}\text { Incremental Cost } \\
\text { per ACR70 } \\
\text { Achieved }\end{array}$ \\
\hline \multicolumn{8}{|c|}{ Payer perspective ( $\mathrm{RCl}$ versus SoC) } \\
\hline 2 & $\$ 183,965$ & 1.591 & $\$ 115,629$ & $\$ 339$ & $\$ 822$ & $\$ 1,459$ & $\$ 3,123$ \\
\hline 3 & $\$ 202,315$ & 2.336 & $\$ 86,607$ & $\$ 252$ & $\$ 687$ & $\$ 1,378$ & $\$ 3,290$ \\
\hline \multicolumn{8}{|c|}{ Societal perspective ( $\mathrm{RCl}$ versus SoC) } \\
\hline 2 & $\$ 117,443$ & 1.591 & $\$ 73,817$ & $\$ 216$ & $\$ 525$ & $\$ 931$ & $\$ 1,994$ \\
\hline 3 & $\$ 104,506$ & 2.336 & $\$ 44,737$ & $\$ 130$ & $\$ 355$ & $\$ 7 / 2$ & $\$ 1,699$ \\
\hline
\end{tabular}

Notes: Results presented on a per-person basis (I,000 simulations); ${ }^{\text {a }}$ positive value represents the cost incurred with the $\mathrm{RCl}$ and improvement in QALY with the RCl, and vice versa.

Abbreviations: ACR, American College of Rheumatology; ICER, incremental cost-effectiveness ratio; LDA, low disease activity; QALY, quality-adjusted life-year; RCI, repository corticotropin injection; SoC, standard of care; USD, United States Dollars. 


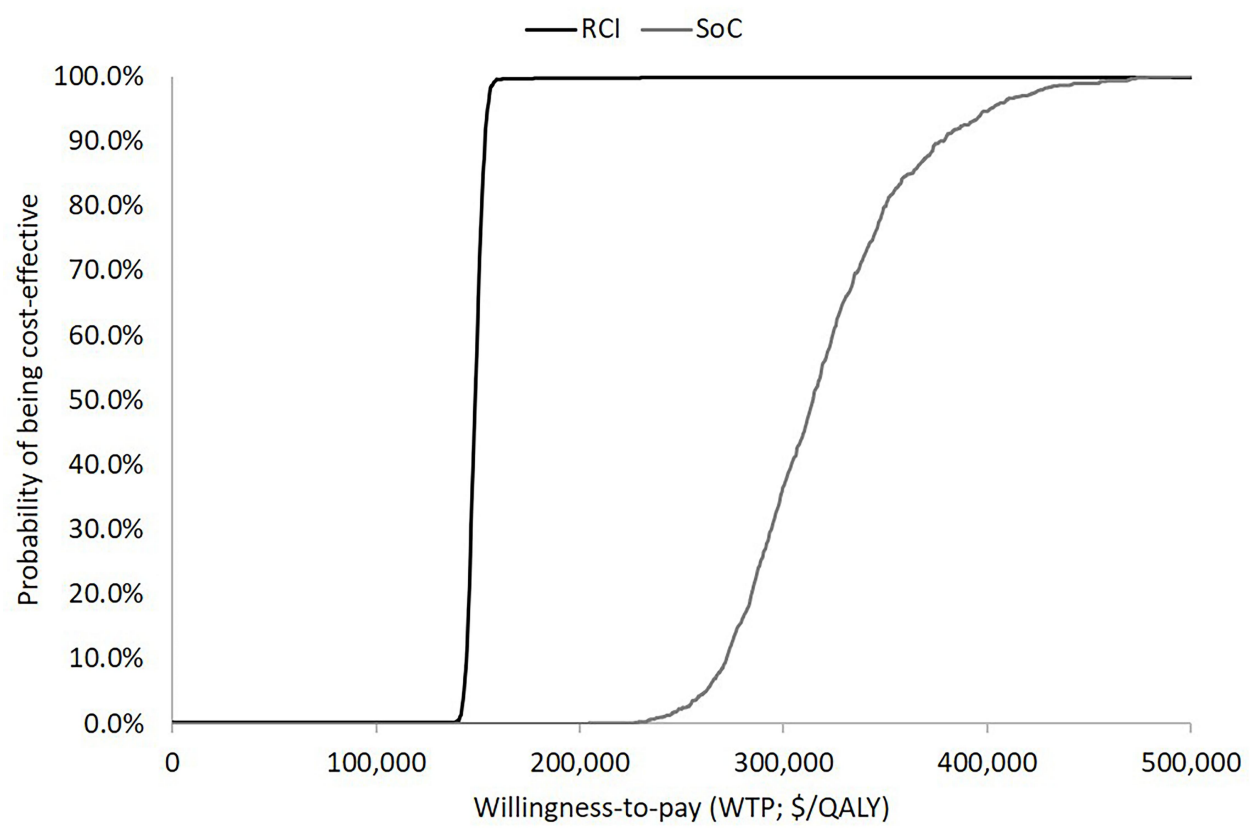

Figure 2 Cost-effectiveness acceptability curve of $\mathrm{RCl}$ and SoC. Based on 1,000 model iterations performed in the PSA.

Abbreviations: PSA, probabilistic sensitivity analysis; QALY, quality-adjusted life-year; RCl, repository corticotropin injection; SoC, standard of care; WTP, willingness-to-pay.

to account for uncertainty in the parameters. The findings were consistent with base case analyses.

\section{Conclusions}

RCI is a cost-effective strategy for patients with persistently active RA who are previously treated with disease-modifying anti-rheumatic drugs and corticosteroids compared to SoC over two to three years from the payer and societal perspectives at a US willingness-to-pay threshold of $\$ 150,000$ per QALY. RCI is also a cost-benefit approach for improving clinical outcomes including achievement of LDA, ACR 20, ACR50, and ACR 70 outcomes. Further research is required to examine the long-term clinical effectiveness and costeffectiveness of RCI for active RA. This study suggests that the use of RCI for patients with active disease despite aggressive treatment may considerably improve a patient's clinical and health outcomes and provide economic benefits.

\section{Author Contributions}

All authors made a significant contribution to the work reported, including study conception, design, execution, acquisition of data, analysis and interpretation, and in all these areas; took part in drafting, revising or critically reviewing the article; gave final approval of the version to be published; have agreed on the journal to which the article has been submitted; and agree to be accountable for all aspects of the work.

\section{Funding}

This study was sponsored by Mallinckrodt Pharmaceuticals.

\section{Disclosure}

$\mathrm{JB}$ is an employee of Falcon Research Group. IC was a research collaborator for the duration of this study and has no disclosures. GJW and JN are employees at Mallinckrodt Pharmaceuticals. MP is a consultant providing services on behalf of Mallinckrodt Pharmaceuticals. The authors report no other conflicts of interest in this work.

\section{References}

1. Zerbini CAF, Clark P, Mendez-Sanchez L, et al. Biologic therapies and bone loss in rheumatoid arthritis. Osteoporos Int. 2017;28(2):429-446. doi:10.1007/s00198-016-3769-2

2. Smolen JS, Aletaha D, Barton A, et al. Rheumatoid arthritis. Nat Rev Dis Primers. 2018;4:18001.

3. Akil M, Moots R. Rheumatoid arthritis: clinical features and diagnosis. In: ABC of Rheumatology. 5th ed. Oxford: Wiley; 2018:73-76.

4. Scott DL, Wolfe F, Huizinga TW. Rheumatoid arthritis. Lancet. 2010;376(9746):1094-1108. doi:10.1016/S0140-6736(10)60826-4

5. Helmick CG, Felson DT, Lawrence RC, et al. Estimates of the prevalence of arthritis and other rheumatic conditions in the United States. Part I. Arthritis Rheum. 2008;58(1):15-25. doi:10.1002/ art. 23177

6. Greenapple R. Trends in biologic therapies for rheumatoid arthritis: results from a survey of payers and providers. Am Health Drug Benefits. 2012;5(2):83-92.

7. Arthritis Foundation. Rheumatoid arthritis treatment; 2020. Available from: https://www.arthritis.org/diseases/rheumatoid-arthritis. Accessed July 20, 2020. 
8. Smolen JS, Landewe R, Bijlsma J, et al. EULAR recommendations for the management of rheumatoid arthritis with synthetic and biological disease-modifying antirheumatic drugs: 2016 update. Ann Rheum Dis. 2017;76(6):960-977. doi:10.1136/annrheumdis-2016210715

9. Singh JA, Saag KG, Bridges SL, et al. 2015 American college of rheumatology guideline for the treatment of rheumatoid arthritis. Arthritis Care Res. 2016;68(1):1-25. doi:10.1002/acr.22783

10. Smolen JS, Aletaha D. Rheumatoid arthritis therapy reappraisal: strategies, opportunities and challenges. Nat Rev Rheumatol. 2015;11(5):276-289. doi:10.1038/nrrheum.2015.8

11. Taylor PC, Moore A, Vasilescu R, Alvir J, Tarallo M. A structured literature review of the burden of illness and unmet needs in patients with rheumatoid arthritis: a current perspective. Rheumatol Int. 2016;36(5):685-695. doi:10.1007/s00296-015-3415-x

12. Kearsley-Fleet L, Davies R, De Cock D, et al. Biologic refractory disease in rheumatoid arthritis: results from the British society for rheumatology biologics register for rheumatoid arthritis. Ann Rheum Dis. 2018;77(10):1405-1412. doi:10.1136/annrheumdis-2018-213378

13. Atzinger CB, Guo JJ. Biologic disease-modifying antirheumatic drugs in a national, privately insured population: utilization, expenditures, and price trends. Am Health Drug Benefits. 2017;10 (1):27-36.

14. Desai RJ, Solomon DH, Jin Y, Liu J, Kim SC. Temporal trends in use of biologic DMARDs for rheumatoid arthritis in the United States: a cohort study of publicly and privately insured patients. J Manag Care Spec Pharm. 2017;23(8):809-814. doi:10.18553/jmcp.2017.23.8.809

15. Bijlsma JW, Boers M, Saag KG, Furst DE. Glucocorticoids in the treatment of early and late RA. Ann Rheum Dis. 2003;62 (11):1033-1037. doi:10.1136/ard.62.11.1033

16. Mallinckdrodt Pharmaceuticals. Acthar $^{\circledR}$ Gel [package insert]. New Jersey, USA: Mallinckdrodt Pharmaceuticals H; February 2021.

17. Catania A, Lonati C, Sordi A, Carlin A, Leonardi P, Gatti S. The melanocortin system in control of inflammation. ScientificWorldJournal. 2010;10:1840-1853. doi:10.1100/tsw.2010.173

18. Fleischmann R, Furst DE, Connolly-Strong E, Liu J, Zhu J, Brasington R. Repository corticotropin injection for active rheumatoid arthritis despite aggressive treatment: a randomized controlled withdrawal trial. Rheumatol Ther. 2020;7(2):327-344. doi:10.1007/ s40744-020-00199-3

19. Ho-Mahler N, Turner B, Eaddy M, Hanke ML, Nelson WW. Treatment with repository corticotropin injection in patients with rheumatoid arthritis, systemic lupus erythematosus, and dermatomyositis/polymyositis. Open Access Rheumatol. 2020;12:21-28. doi:10.2147/OARRR.S231667

20. Wu B, Deshpande G, Gu T, Popelar B, Philbin M, Wan GJ. Demographics, treatment patterns, and healthcare utilization and cost of repository corticotropin injection in patients with systemic lupus erythematosus or rheumatoid arthritis. J Med Econ. 2017;20 (11):1170-1177. doi:10.1080/13696998.2017.1362411

21. van der Heijde DM, van 'T Hof MA, van Riel PL, et al. Judging disease activity in clinical practice in rheumatoid arthritis: first step in the development of a disease activity score. Ann Rheum Dis. 1990;49 (11):916-920. doi:10.1136/ard.49.11.916

22. van der Kooi E, Klarenbeek NB, Guler-Yuksel M, et al. A decrease in disease activity score (DAS) level is associated with a decrease in health assessment questionnaire (HAQ) score, independent of follow-up duration, during 5 years of tightly controlled treatment: results from the BeSt study. Ann Rheum Dis. 2011;70(1):168-171. doi:10.1136/ard.2010.133132

23. Kim HL, Kim D, Jang EJ, et al. Mapping health assessment questionnaire disability index (HAQ-DI) score, pain visual analog scale (VAS), and disease activity score in 28 joints (DAS28) onto the EuroQol-5D (EQ-5D) utility score with the KORean observational study network for arthritis (KORONA) registry data. Rheumatol Int. 2016;36(4):505-513. doi:10.1007/s00296-016-3427-1
24. Onuoha KO, Solow M, Newman JM, et al. Have the annual trends of total hip arthroplasty in rheumatoid arthritis patients decreased? Ann Transl Med. 2017;5(Suppl 3):S35. doi:10.21037/atm.2017.11.15

25. Clair AJ, Evangelista PJ, Lajam CM, Slover JD, Bosco JA, Iorio R. Cost analysis of total joint arthroplasty readmissions in a bundled payment care improvement initiative. J Arthroplasty. 2016;31 (9):1862-1865. doi:10.1016/j.arth.2016.02.029

26. Boonstra AM, Schiphorst Preuper HR, Balk GA, Stewart RE. Cut-off points for mild, moderate, and severe pain on the visual analogue scale for pain in patients with chronic musculoskeletal pain. Pain. 2014;155(12):2545-2550. doi:10.1016/j.pain.2014.09.014

27. Lalonde L, Choiniere M, Martin E, Berbiche D, Perreault S, Lussier D. Costs of moderate to severe chronic pain in primary care patients - a study of the ACCORD program. $J$ Pain Res. 2014;7:389-403. doi:10.2147/JPR.S55388

28. Day AL, Curtis JR. Opioid use in rheumatoid arthritis: trends, efficacy, safety, and best practices. Curr Opin Rheumatol. 2019;31 (3):264-270. doi:10.1097/BOR.0000000000000602

29. Lee YC, Kremer J, Guan H, Greenberg J, Solomon DH. Chronic opioid use in rheumatoid arthritis: prevalence and predictors. Arthritis Rheumatol. 2019;71(5):670-677. doi:10.1002/art.40789

30. White AG, Birnbaum HG, Mareva MN, et al. Direct costs of opioid abuse in an insured population in the United States. J Manag Care Pharm. 2005;11(6):469-479. doi:10.18553/jmcp.2005.11.6.469

31. Bureau of Labor Statistics. National occupational employment and wage estimates United States; 2019. Available from: https://www.bls. gov/oes/current/oes nat.htm\#00-0000. Accessed September 13, 2020.

32. Birnbaum HG, Ivañova JI, Samuels S, et al. Economic impact of multiple sclerosis disease-modifying drugs in an employed population: direct and indirect costs. Curr Med Res Opin. 2009;25 (4):869-877. doi:10.1185/03007990902743869

33. Stevenson M, Archer R, Tosh J, et al. Adalimumab, etanercept, infliximab, certolizumab pegol, golimumab, tocilizumab and abatacept for the treatment of rheumatoid arthritis not previously treated with disease-modifying antirheumatic drugs and after the failure of conventional disease-modifying antirheumatic drugs only: systematic review and economic evaluation. Health Technol Assess. 2016;20(35):1-610.

34. Hernandez Alava M, Wailoo AJ, Ara R. Tails from the peak district: adjusted limited dependent variable mixture models of EQ-5D questionnaire health state utility values. Value Health. 2012;15 (3):550-561. doi:10.1016/j.jval.2011.12.014

35. Dubois RW. Cost-effectiveness thresholds in the USA: are they coming? Are they already here? J Comp Eff Res. 2016;5(1):9-11. doi: $10.2217 /$ cer. 15.50

36. Institute for Clinical and Economic Review. 2020-2023 value assessment framework; 2020.

37. Porter ME. What is value in health care? N Engl J Med. 2010;363 (26):2477-2481. doi:10.1056/NEJMp1011024

38. International Business Machines. Micromedex ${ }^{\circledR}$ RED BOOK; 2020. Available from: https://www.micromedexsolutions.com/home/dis patch/ssl/true. Accessed November 20, 2020.

39. ClinicaTrials.gov (NCT02919761). Safety and effectiveness of acthar gel in participants with rheumatoid arthritis; 2020. Available from: https:// clinicaltrials.gov/ct2/show/NCT02919761. Accessed July 20, 2020.

40. Eisenberg Center at Oregon Health \& Science University. Choosing medications for rheumatoid arthritis: clinician's guide. In: Comparative Effectiveness Review Summary Guides for Clinicians. Rockville, MD; 2007.

41. Klimes J, Vocelka M, Sedova L, et al. Medical and productivity costs of rheumatoid arthritis in the Czech Republic: cost-of-illness study based on disease severity. Value Health Reg Issues. 2014;4:75-81. doi:10.1016/j.vhri.2014.07.004

42. Myung G, Nelson WW, McMahon MA. Effects of repository corticotropin injection on medication use in patients with rheumatologic conditions: a claims data study. J Pharm Technol. 2017;33 (4):151-155. doi:10.1177/8755122517709825 


\section{Publish your work in this journal}

ClinicoEconomics and Outcomes Research is an international, peerreviewed open-access journal focusing on Health Technology Assessment, Pharmacoeconomics and Outcomes Research in the areas of diagnosis, medical devices, and clinical, surgical and pharmacological intervention. The economic impact of health policy and health systems

Submit your manuscript here: https://www.dovepress.com/clinicoeconomics-and-outcomes-research-journal organization also constitute important areas of coverage. The manuscript management system is completely online and includes a very quick and fair peer-review system, which is all easy to use. Visit http://www.dovepress.com/testimonials.php to read real quotes from published authors. 